\title{
EFEITO COMBINADO DE CONDIÇÕES ALTERADAS DURANTE A FERMENTAÇÃO SOBRE A ATIVIDADE DE INVERTASE DE LEVEDURA ENOLÓGICA COMERCIAL
}

\author{
R. F. D’AVILA ${ }^{1}$, E. FICAGNA ${ }^{2}$, S. D. S. da SILVA ${ }^{3}$, M. H. BRUSCATTO ${ }^{1}$, C. T. SOUSA ${ }^{4}$ e R. P. \\ TORALLES ${ }^{5}$ \\ ${ }^{1}$ Universidade Federal de Pelotas, Departamento de Ciência e Tecnologia Agroindustrial \\ ${ }^{2}$ Instituto Federal Rio Grande do Sul, Departamento de Viticultura e Enologia \\ ${ }^{3}$ Universidade Federal de Pelotas, Departamento de Nutrição \\ ${ }^{4}$ Universidade Federal de Pelotas, Centro de Ciências Químicas, Farmacêuticas e de Alimentos \\ ${ }^{5}$ Instituto Federal Sul-Riograndense, Departamento de Química \\ E-mail para contato: roseane.davila@gmail.com
}

\begin{abstract}
RESUMO - O processo de correção de açúcares em mosto visa elevar o teor alcoólico dos vinhos produzidos. A sacarose comumente adicionada precisa ser hidrolisada pela enzima invertase secretada pela levedura Saccharomyces cerevisiae durante a fermentação. Porém, durante o processo, o meio sofre alterações pelo aumento da concentração de álcool, temperatura e acidez, além da presença de sulfitos adicionados. Este trabalho teve por objetivo caracterizar o quanto a atividade da enzima invertase é alterada por modificações nestas variáveis. Como resultados observou-se que a diminuição do $\mathrm{pH}$ foi o principal fator que fez decair a atividade enzimática, mesmo às condições de concentração de etanol e temperatura ideais. Quando comparadas estas duas variáveis, observa-se que não há perdas consideráveis da atividade na temperatura ótima da invertase e que a menor atividade observada em temperaturas menores somente ocorre quando o meio possui concentração de etanol mais elevada. A adição de sulfito não se mostrou significativa.
\end{abstract}

\section{INTRODUÇÃO}

O vinho é a bebida resultante exclusivamente da fermentação completa ou parcial da uva fresca. Sua composição é complexa, possuindo açúcares, álcoois variados (dentre os quais o álcool etílico é o principal, com até $20 \%$ dependendo do tipo de vinho desejado), água, diferentes ácidos livres ou combinados (responsáveis pela acidez fixa e volátil). As condições climáticas da safra vitícola exercem influência preponderante nas características da uva e, consequentemente, na composição do vinho. Assim, existe uma influência do clima nas concentrações de açúcar e de ácidos orgânicos, no teor de compostos voláteis e de compostos fenólicos da uva, variáveis que determinam a estrutura e a cor dos vinhos, importantes fatores para sua qualidade (Rizzon e Miele, 2006).

Em safras onde a maturação das uvas não alcança nível satisfatório, especialmente devido as condições climáticas, é comumente realizado o processo de chaptalização, prática enológica que consiste em corrigir o teor de açúcar no mosto para aumentar a graduação alcoólica do vinho em no 


\section{9 a 22 de outubro de 2014 \\ Florianópolis/SC}

máximo 3\% (v/v) estabelecida pela legislação brasileira (Brasil, 2004). O teor alcoólico dos vinhos produzido durante o processo fermentativo está diretamente vinculado ao teor de açúcares fermentescíveis existentes na uva a ser vinificada.

A fermentação alcoólica é a transformação anaeróbica de açúcares, sobretudo glucose e frutose, em etanol e dióxido de carbono. No entanto, este é um processo muito mais complexo. Ao mesmo tempo em que esta reação se processa, uma série de outros processos bioquímicos, químicos e físicoquímicas ocorrem, tornando possível a transformação do mosto de uva em vinho. Além de etanol, vários outros compostos são produzidos durante toda a fermentação alcoólica, tais como álcoois superiores, ésteres de glicerol, ácido succínico, diacetil, acetoína e 2,3-butanodiol. Ao mesmo tempo, alguns outros compostos do mosto também são convertidos pelo metabolismo das leveduras. Sem a produção dessas outras substâncias, o vinho teria pouco interesse organoléptico (Zamora, 2009). Embora o processo possa ser realizado pelas leveduras nativas (autóctones) presentes na uva, para garantia e uniformidade na fermentação alcoólica utiliza-se levedura selecionada, disponível na forma de levedura seca ativa (Rizzon e Dall`Agnol, 2007).

A levedura mais utilizada na vinificação é a Saccharomyces cerevisiae, uma das principais produtoras da enzima invertase ( $\beta$-D-frutofuranosidase frutohidrolase E.C.3.2.1.26), identificada de duas diferentes formas: a glicosilada que está localizada no espaço periplasma e encontra-se associada à parede celular da levedura e, outra que não é glicosilada e está concentrada no citoplasma (Zarate e Belda, 1996). A atividade invertase da levedura está relacionada com a invertase do periplasma que hidrolisa a sacarose produzindo uma mistura equimolar de glicose e frutose. Esta enzima tem sido empregada para melhorar a utilização de certos substratos tais como nos processos de fermentação alcoólica (Takeshige e Ouchi, 1995).

As enzimas trabalham de forma máxima em valores específicos de $\mathrm{pH}$, temperaturas e concentrações de substrato. Assim como toda a enzima, a invertase está sujeita à inibição pela alteração dos componentes do meio. Apresentam pH ótimo de 4,0 a 5,5, sendo inativadas em meios com $\mathrm{pH}$ superior a 6,0 e inferior a 3,0. As invertases apresentam temperaturas ótimas de $55^{\circ} \mathrm{C}$ para soluções diluídas de sacarose e de $65^{\circ} \mathrm{C}$ a $70^{\circ} \mathrm{C}$ para soluções com concentração superior a $10 \%$ (Koblitz, 2010). A concentração de álcool durante a fermentação também exerce papel fundamental na atividade enzimática. Sendo assim, quanto maior a concentração do produto, menor será a atividade enzimática, uma vez que a diminuição da concentração do substrato passa a ser significativa, a reação prosseguirá com velocidades cada vez menores, até que todo o substrato seja transformado em produto (Marzzoco e Torres, 2007).

A substância mais útil para proteger o vinho contra oxidações é o dióxido de enxofre $\left(\mathrm{SO}_{2}\right)$ apresentando características antissépticas, antioxidantes e inibidoras de enzimas oxidativas (RibéreauGayon et al., 2006). A forma mais comum de utilização deste composto são os sais, principalmente metabissulfito de potássio, que apresenta como características a ação solubilizante, ação antioxidásica e ação coagulante (Giovannini e Manfroi, 2009). A quantidade de metabissulfito de potássio a ser adicionada ao mosto, logo após o esmagamento da uva, depende de sua qualidade, mas de 8 a $12 \mathrm{~g} / \mathrm{hL}$ de mosto são suficientes para garantir um efeito anti-séptico contra as bactérias acéticas, láticas e leveduras indesejáveis. Entretanto, doses muito altas, retardam a fermentação alcoólica, causam odor 
desagradável e podem afetar a saúde do consumidor (Rizzon \& Dall Agnol, 2007).

Com base no exposto, o objetivo desta pesquisa foi determinar a influencia das variáveis $\mathrm{pH}$, temperatura e concentração de álcool e de $\mathrm{SO}_{2}$ sobre a atividade da enzima invertase oriunda de uma levedura enológica comercial Saccharomyces cerevisiae.

\section{MATERIAIS E MÉTODOS}

O experimento foi conduzido no Laboratório de Frutas e Hortaliças da Universidade Federal de Pelotas, Pelotas-RS. A enzima foi extraída de uma levedura enológica comercial Saccharomyces cerevisiae através de agitação em meio alcalino $(\mathrm{pH} 9,0)$ por $24 \mathrm{~h}$ e posterior centrifugação (5.000 rpm) por 5 minutos. As proteínas foram quantificadas segundo a metodologia de Biureto, utilizando o soro albumina bovina (BSA) como padrão.

A atividade da invertase foi determinada através da quantificação da glicose produzida pela ação da invertase com o reagente ácido 3,5-dinitrosalicílico. Para determinar o efeito combinado dos fatores $\mathrm{pH}$, temperatura, presença de dióxido de enxofre e concentração de etanol, de modo a simular características do mosto durante o processo de vinificação, foi utilizado delineamento com planejamento composto central para 4 fatores, conforme as codificações da matriz mostradas na Tabela 1, onde X1, X2, X3 e X4 correspondem às variáveis $\mathrm{pH}$, etanol, concentração de $\mathrm{SO}_{2} \mathrm{e}$ temperatura. O ponto central (ensaio 25) foi replicado seis vezes e os demais pontos foram replicados duas vezes. $\mathrm{O}$ meio reacional consistiu de $1 \mathrm{~mL}$ do extrato enzimático, $1 \mathrm{~mL}$ de solução de sacarose $0,2 \mathrm{M}$, e $1 \mathrm{~mL}$ de soluções com diferentes concentrações de $\mathrm{pH}$, etanol e metabissulfito de sódio, conforme a matriz experimental exposta na Tabela 2, totalizando $5 \mathrm{~mL}$. As reações ocorreram durante 10 minutos, tempo em que as amostras permaneceram nas temperaturas indicadas na matriz experimental. Após, os açúcares redutores formados reagiram com $1 \mathrm{~mL}$ de ácido 3,5-dinitrosalicílico durante 5 minutos, as amostras foram diluídas e sua absorbância foi lida a $490 \mathrm{~nm}$ (Miller, 1959). A glicose foi utilizada como padrão e uma unidade de atividade enzimática foi definida como a quantidade de enzimas que libera $1 \mu \mathrm{mol}$ de açúcar redutor por minuto nas condições de ensaio.

Tabela 1 - Codificação das variáveis reacionais e planejamento do experimento

\begin{tabular}{ccccc}
\hline $\begin{array}{c}\text { Código } \\
\text { de Nível }\end{array}$ & $\mathrm{pH}$ & $\begin{array}{c}{[\mathrm{EtOH}]} \\
(\% \mathrm{v} / \mathrm{v})\end{array}$ & $\begin{array}{c}{\left[\mathrm{SO}_{2}\right]} \\
(\mathrm{ppm})\end{array}$ & $\begin{array}{c}\text { Temperatura } \\
\left({ }^{\circ} \mathrm{C}\right)\end{array}$ \\
\hline-2 & 2,5 & 8,0 & 0 & $\mathrm{X} 3$ \\
-1 & 3,0 & 10,0 & 75 & 20,0 \\
0 & 3,5 & 12,0 & 150 & 30,0 \\
1 & 4,0 & 14,0 & 225 & 40,0 \\
2 & 4,5 & 16,0 & 300 & 50,0 \\
\hline
\end{tabular}


Tabela 2 - Matriz do planejamento experimental com as variáveis codificadas, naturais, resposta (Ya) e número de repetições dos ensaios $(\mathrm{Nb})$

\begin{tabular}{rrrrrrrrrrr}
\hline Ensaio & \multicolumn{9}{c}{ Variáveis codificadas } & \multicolumn{7}{c}{ Variáveis naturais } & Ya & Nb \\
& \multicolumn{1}{c}{ X1 } & \multicolumn{1}{c}{ X2 } & \multicolumn{1}{c}{ X3 } & \multicolumn{1}{c}{ X4 } & X1 & X2 & \multicolumn{1}{c}{ X3 } & X4 & & \\
\hline 1 & $-1,00$ & $-1,00$ & $-1,00$ & $-1,00$ & 3,0 & 10,0 & 75,0 & 20,0 & 382,9 & 2 \\
2 & $-1,00$ & $-1,00$ & $-1,00$ & 1,00 & 3,0 & 10,0 & 75,0 & 40,0 & 537,7 & 2 \\
3 & $-1,00$ & $-1,00$ & 1,00 & $-1,00$ & 3,0 & 10,0 & 225,0 & 20,0 & 391,9 & 2 \\
4 & $-1,00$ & $-1,00$ & 1,00 & 1,00 & 3,0 & 10,0 & 225,0 & 40,0 & 501,8 & 2 \\
5 & $-1,00$ & 1,00 & $-1,00$ & $-1,00$ & 3,0 & 14,0 & 75,0 & 20,0 & 122,6 & 2 \\
6 & $-1,00$ & 1,00 & $-1,00$ & 1,00 & 3,0 & 14,0 & 75,0 & 40,0 & 311,1 & 2 \\
7 & $-1,00$ & 1,00 & 1,00 & $-1,00$ & 3,0 & 14,0 & 225,0 & 20,0 & 255,0 & 2 \\
8 & $-1,00$ & 1,00 & 1,00 & 1,00 & 3,0 & 14,0 & 225,0 & 40,0 & 349,2 & 2 \\
9 & 1,00 & $-1,00$ & $-1,00$ & $-1,00$ & 4,0 & 10,0 & 75,0 & 20,0 & 771,0 & 2 \\
10 & 1,00 & $-1,00$ & $-1,00$ & 1,00 & 4,0 & 10,0 & 75,0 & 40,0 & 730,7 & 2 \\
11 & 1,00 & $-1,00$ & 1,00 & $-1,00$ & 4,0 & 10,0 & 225,0 & 20,0 & 712,7 & 2 \\
12 & 1,00 & $-1,00$ & 1,00 & 1,00 & 4,0 & 10,0 & 225,0 & 40,0 & 537,7 & 2 \\
13 & 1,00 & 1,00 & $-1,00$ & $-1,00$ & 4,0 & 14,0 & 75,0 & 20,0 & 562,4 & 2 \\
14 & 1,00 & 1,00 & $-1,00$ & 1,00 & 4,0 & 14,0 & 75,0 & 40,0 & 665,6 & 2 \\
15 & 1,00 & 1,00 & 1,00 & $-1,00$ & 4,0 & 14,0 & 225,0 & 20,0 & 564,6 & 2 \\
16 & 1,00 & 1,00 & 1,00 & 1,00 & 4,0 & 14,0 & 225,0 & 40,0 & 670,1 & 2 \\
17 & $-2,00$ & 0,00 & 0,00 & 0,00 & 2,5 & 12,0 & 150,0 & 30,0 & 416,5 & 2 \\
18 & 2,00 & 0,00 & 0,00 & 0,00 & 4,5 & 12,0 & 150,0 & 30,0 & 1098,6 & 2 \\
19 & 0,00 & $-2,00$ & 0,00 & 0,00 & 3,5 & 8,0 & 150,0 & 30,0 & 614,0 & 2 \\
20 & 0,00 & 2,00 & 0,00 & 0,00 & 3,5 & 16,0 & 150,0 & 30,0 & 472,6 & 2 \\
21 & 0,00 & 0,00 & $-2,00$ & 0,00 & 3,5 & 12,0 & 0,0 & 30,0 & 531,0 & 2 \\
22 & 0,00 & 0,00 & 2,00 & 0,00 & 3,5 & 12,0 & 300,0 & 30,0 & 555,6 & 2 \\
23 & 0,00 & 0,00 & 0,00 & $-2,00$ & 3,5 & 12,0 & 150,0 & 10,0 & 331,3 & 2 \\
24 & 0,00 & 0,00 & 0,00 & 2,00 & 3,5 & 12,0 & 150,0 & 50,0 & 629,7 & 2 \\
25 & 0,00 & 0,00 & 0,00 & 0,00 & 3,5 & 12,0 & 150,0 & 30,0 & 578,1 & 6 \\
\hline
\end{tabular}

\section{RESULTADOS E DISCUSSÃO}

Na tabela 2, além do delineamento do experimento, têm-se os resultados para a medida da atividade de invertase (Ya), onde o ponto 18 foi aquele que apresentou maior atividade, de 1098,6 $\mu \mathrm{mol}$ de glicose/minuto. Em relação ao ponto central, este se diferenciou pelo $\mathrm{pH}$ do meio, o que demonstra que entre os parâmetros testados, este apresenta diferenças significativas de atividade enzimática entre os pontos (Figura 1d), onde o $\mathrm{pH}$ ótimo foi de 4,5 e abaixo deste ponto a atividade diminuiu. As concentrações de dióxido de enxofre testadas não alteraram a atividade de invertase, conforme pode ser visto na Figura 1a. Uma vez que o máximo de $\mathrm{SO}_{2}$ total em qualquer tipo de vinho, segundo a legislação brasileira, é de $35 \mathrm{mg} / 100 \mathrm{~mL}$ (Brasil, 2004), a concentração de 300 ppm, 
próxima ao limite permitido, não interfere no processo de utilização dos açúcares do mosto pelas enzimas. Segundo Giovannini e Manfroi (2009) as doses de $\mathrm{SO}_{2}$ empregadas comumente durante a vinificação situam-se entre 30 e $150 \mathrm{ppm}$, sendo que entre os principais fatores envolvidos nesta tomada de decisão estão o grau de maturação da uva (relacionada a sua riqueza em açúcar e acidez) e o estado sanitário das mesmas, bem como a temperatura do mosto no momento da adição.

A faixa de temperatura ótima para a enzima situou-se entre 30 e $50^{\circ} \mathrm{C}$, sendo que em uma concentração de etanol abaixo de $12 \%$ (v/v) não se notou diferença significativa para a atividade enzimática (Figuras 1b e 1c).

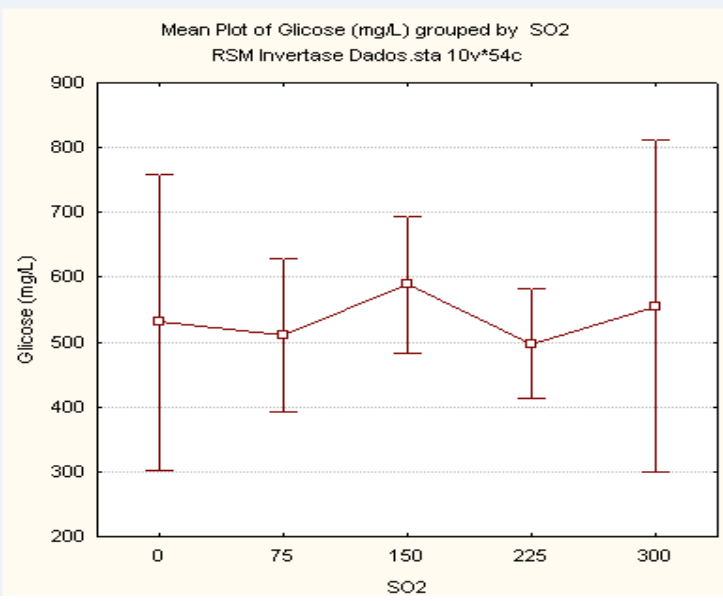

(a)

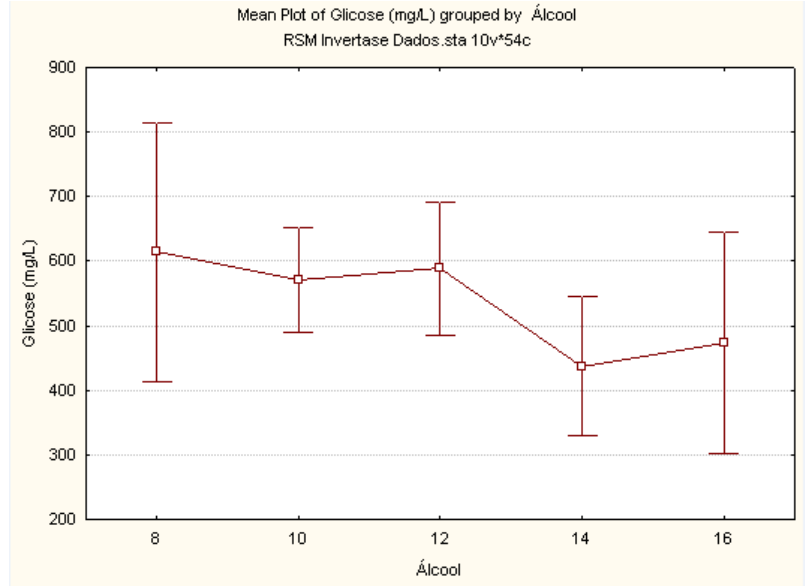

(c)

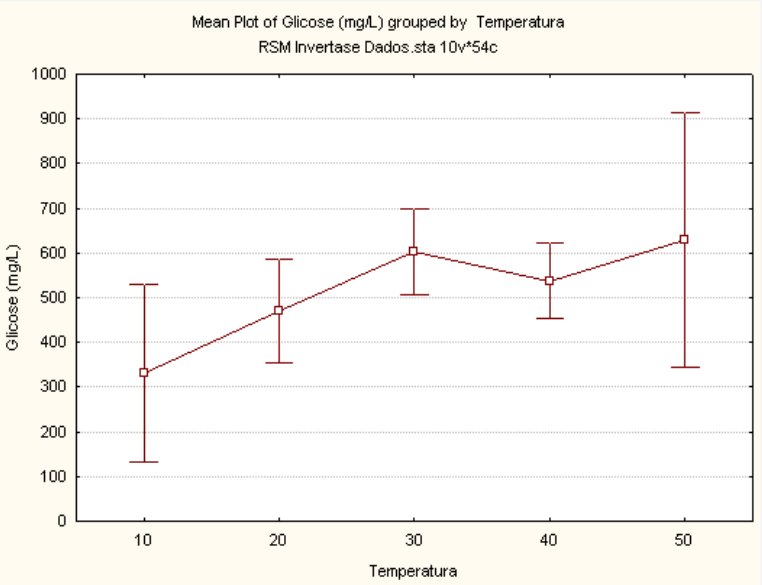

(b)

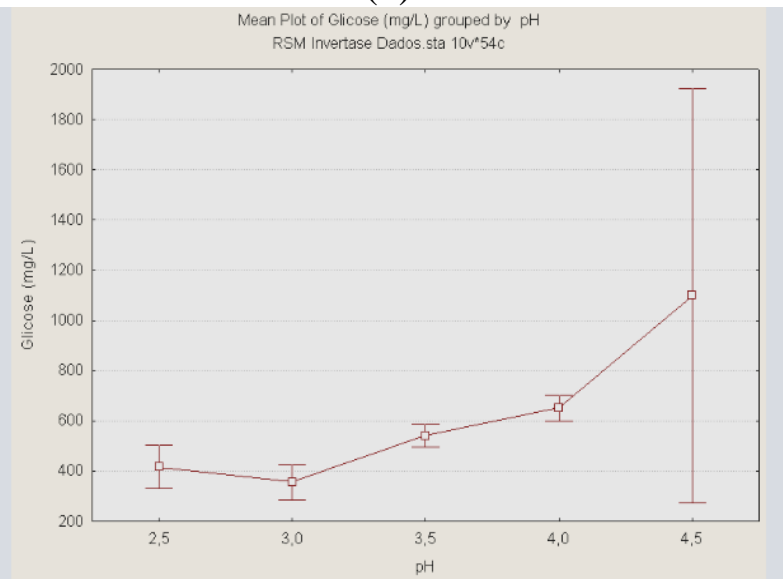

(d)

Figura 1 - Gráfico de médias, máximos e mínimos do tipo Box e Whiskers para a atividade de invertase de levedura enológica comercial para efeito individual da concentração de metabissulfito $\left(\mathrm{SO}_{2}\right)$ (a), da temperatura (b), da concentração de álcool (c) e do pH do meio (d).

$\mathrm{Na}$ análise de superfície de resposta observou-se que em uma faixa de $\mathrm{pH}$ abaixo de 4 há a diminuição da atividade enzimática, principalmente em concentrações superiores a $12 \%$ (v/v) de 
álcool no meio (Figura 2a). Temperaturas de aproximadamente $35^{\circ} \mathrm{C}$ mostraram-se ótimas para a atuação enzimática. A presença de alta concentração de ácidos, e, por conseguinte pH baixo (menor do que 3,4), revelou-se o fator que promoveu maior redução na atividade em temperaturas abaixo de $20^{\circ} \mathrm{C}$, conforme Figura $2 \mathrm{~b}$. Em faixas de $\mathrm{pH}$ próximas a 4 , os ensaios mostraram maior estabilidade da atividade enzimática frente a redução das temperaturas.

Quando comparados os efeitos da concentração de etanol e temperatura, observa-se que quanto maior a concentração de etanol no meio, menor a atividade enzimática e o efeito é pronunciado a temperaturas baixas; as temperaturas elevadas favorecem a atividade enzimática mesmo quando a concentração de etanol atinge níveis elevados (16\% v/v) (Figura 2c).



Legenda:


(a)

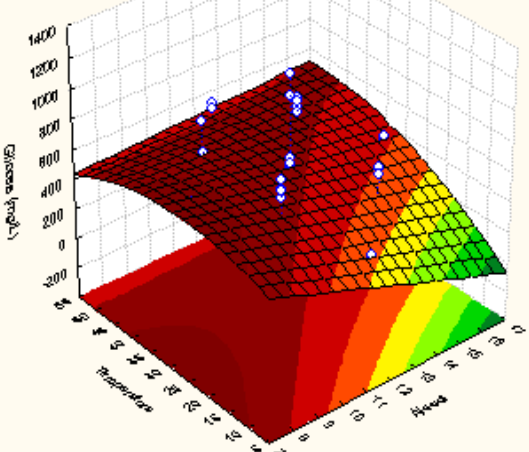

(c)

Figura 2 - Efeito interativo dos parâmetros pH (X1) e concentração de álcool (X2) (a), pH (X1) e temperatura (X4) (b) e concentração de álcool (X2) e temperatura (X4) (c) sobre a atividade de

invertase obtida de levedura enológica comercial utilizando sacarose $0,2 \mathrm{M}$ como substrato.

Segundo Porntaveewat et al. (1990), as condições de atuação enzimática para invertase purificada de uvas Muscat Bailey A são de pH de 2,7-6,4, apresentando atividade ótima a 3,5 e demonstrando termo estabilidade. Neste trabalho, demonstrou-se que as condições de pH próximas de 4,5 foram consideradas mais ideiais, porém o $\mathrm{pH}$ de mostos de diferentes cultivares como Merlot, Cabernet Franc e Cabernet Sauvignon tende a condições ácidas logo após o esmagamento da uva, de aproximadamente 3 a 3,3, chegando a 3,2 - 4 após a fermentação maloláctica e estabilização tartárica; além disso, mostos com $\mathrm{pH}$ menos ácido possuem maior susceptibilidade à reações oxidativas e biológicas (Rizzon et al., 1998).

Nakanishi e Yokotsuka (1990) comentam que invertases obtidas de uvas viníferas apresentam 


\section{9 a 22 de outubro de 2014 \\ Florianópolis/SC}

alta estabilidade térmica, com temperatura ótima em torno de $75^{\circ} \mathrm{C}$, além de atuarem em diferentes faixas de $\mathrm{pH}$, altas concentrações de álcool e de $\mathrm{SO}_{2}$. Morata et al. (2006), em experimentos utilizando diferentes condições de fermentação de vinhos tintos para Sacharomyces cerevisiae e Sacharomyces uvarum, empregaram temperatura de 20 e $30^{\circ} \mathrm{C}$, concentração de $\mathrm{SO}_{2}$ de 0,15 ou 30 $\mathrm{mg} / \mathrm{l}$ e valores de $\mathrm{pH}$ de $3,2,3,7$ ou 4,2. As condições utilizadas nas fermentações abrangem as condições aqui testadas. Na faixa de $20-30^{\circ} \mathrm{C}$, a condição ideal para atividade da enzima invertase seria um pH menos ácido (Fig. 3), próximo à condição de 4,2 testada pelos autores. A $20^{\circ} \mathrm{C}$ se tem uma redução de aproximadamente $50 \%$ da atividade próximo a concentração de etanol de $13 \%$, enquanto que a $30^{\circ} \mathrm{C}$ há uma maior resistência ao aumento da concentração alcoólica (Fig. 4). Com relação à concentração de $\mathrm{SO}_{2}$, foram testadas aqui condições com quantidades mais elevadas, não ocorrendo diferença significativa nesta variável.

Concentrações de álcool (\% v/v) em vinhos provenientes de uvas Cabernet Sauvignon de diferentes safras apresentaram valores de 9,7 até 12,6 (Rizzon e Miele, 2002) e de vinho de uvas Isabel, de 8 a 9,5 (Rizzon e Miele, 2006). Tal valor dependeu do potencial alcóolico do mosto, uma vez que não foram adicionadas outras fontes de açúcares. Como com a chaptalização o potencial alcóolico alcançado é superior, se justifica o estudo de concentrações maiores sobre a atividade da enzima. Com relação a esta variável, quando a enzima é parcialmente inibida pela concentração alcóolica, já foram alcançados valores elevados do componente.

\section{CONCLUSÃO}

As condições utilizadas durante a fermentação propiciam a atuação da enzima invertase sobre os açúcares adicionados ao mosto, sendo que a concentração de $\mathrm{SO}_{2}$ foi o único fator avaliado que não afetou em nenhum nível o parâmetro testado. $\mathrm{O}$ pH ótimo da enzima é mais alto do que o encontrado normalmente em mostos e, juntamente com o aumento da concentração alcoolica que ocorre durante a fermentação, é fator que reduz a atividade enzimática. A temperatura ótima encontrada foi de $35^{\circ} \mathrm{C}$, não sendo este um fator limitante para a invertase durante a fermentação, especialmente em vinhos tintos.

\section{REFERÊNCIAS}

BARLIKOVA, A.; SVORE, J. E MIERTUS, S. Hybrid biosensor for determinations of sucrose. Analytica Chimica Acta, v. 247, p. 83-87, 1991.

BRASIL. Lei $n$. 10970 de 16 de novembro de 2004. Altera dispositivos da Lei $\mathrm{n} .7678$ de 8 de novembro de 1988, que dispõe sobre a produção, circulação e comercialização do vinho e derivados de uva e do vinho, e dá outras providências. DOU: Diário Oficial da União, Brasília, DF, 2004.

GIOVANNINI, E.; MANFROI, V. Viticultura e enologia: elaboração de grandes vinhos nos terroirs brasileiros. Bento Gonçalves: IFRS, 2009. 344p. 
KOBLITZ, M. G. B. Bioquímica de alimentos: teoria e aplicações práticas. Rio de Janeiro: Editora Guanabara Koogan, 2010, 242p.

MARZZOCO, A.; TORRES, B. B. Bioquímica básica. Rio de Janeiro: Editora Guanabara Koogan, 2007, 386p.

MILLER, G. L. Use of Dinitrosalicylic Acid Reagent for Determination of Reducing Sugar. Analytical Chemistry, v. 31, p. 426-428, 1959.

MORATA, A.; GÓMEZ-CORDOVÉS, M. C.; CALDERÓN, F.; SUÁREZ, J. A. Effects of pH, temperature and $\mathrm{SO}_{2}$ on the formation of pyranoanthocyanins during red wine fermentation with two species of Saccharomyces. International Journal of Food Microbiology, v. 106, p. 123-129, 2006.

NAKANISHI, K.; YOKOTSUKA, K.; Characterization of Thermostable Invertase from Wine Grapes. Journal of Fermentation and Bioengineering, v. 69, n. 1, p. 16-22, 1990.

PORNTAVEEWAT, W.; TAKAYANAGI, T.; YOKOTSUKA, K. Purification and Properties of Invertase from Muscat Bailey A. Grapes. Journal of Fermentation and Bioengineering, v. 78, n. 4, p. 288-292, 1994.

RIBÉREAU-GAYON, P., DUBOURDIEU, D.; DONÈCHE, B.; LONVAUD, A. Handbook of Enology, The microbiology of wine and vinifications. Vol. 1. John Wiley \& Sons, 2006.

RIZZON, L. A.; MIELE, A. Avaliação da cv. Cabernet Sauvignon para elaboração de vinho tinto. Ciência e Tecnologia de Alimentos, v. 22, n. 2, p. 192-198, 2002.

RIZZON, L. A.; MIELE, A. Efeito da safra vitícola na composição da uva, do mosto e do vinho Isabel da Serra Gaúcha, Brasil. Ciência Rural, v. 36, n. 3, p. 959-964, 2006.

RIZZON, L.A.; DALL'AGNOL, I. Vinho tinto. Sistemas de Produção - Agroindústria Familiar Bento Gonçalves: EMBRAPA Uva e Vinho, 45p. 2007.

RIZZON, L.A.; ZANUZ, M. C.; MIELE, A. Evolução da acidez durante a vinificação de uvas tintas de três regiões vitícolas do Rio Grande do Sul. Ciência e Tecnologia de Alimentos, v. 18, n. 2, p. 179$183,1998$.

TAKESHIGE, K.; OUCHI, K. Effects of yeast invertase on ethanol production in molasses. $J$. Fermentation Bioengineering, v. 79, p. 513-515. 1995.

ZAMORA, Fernando. Biochemistry of alcoholic fermentation. In: Wine Chemistry and Biochemistry. Springer New York, p. 3-26. 2009.

ZÁRATE, V.; BELDA, F. Characterization of the heterologous invertase produced by Schizosaccharomyces pombe from the SUC2 gene of Saccharomyces cerevisiae. Journal of Applied Bacteriology, v. 80, n. 1, p. 45-52, 1996. 